\title{
NUMERICAL MODELING OF STORM SURGE INDUCED BY MAY 2009 EAST COAST LOW IN GOLD COAST, AUSTRALIA
}

\author{
Aliasghar Golshani ${ }^{1}$, Will Thurston ${ }^{2}$, Deborah J. Abbs ${ }^{3}$, Greg Stuart ${ }^{4}$, Rodger \\ Tominson $^{4}$
}

1. Griffith Centre for Coastal Management, Gold Coast Campus, Griffith University, QLD 4222, Australia. a.golshani@griffith.edu.au

2. Griffith Centre for Coastal Management, Gold Coast Campus, Griffith University, QLD 4222.will.thurston@csiro.au

3. CSIRO Marine and Atmospheric Research, Private Bag 1, Aspendale, VIC 3195, Australia. deborah.abbs@csiro.au

4. DHI Water and Environment, Southport, QLD 4215, Australia. gbs@dhigroup.com

5. Griffith Centre for Coastal Management, Gold Coast Campus, Griffith University, QLD 4222, Australia. r.tomlinson@griffith.edu.au

\begin{abstract}
The East Coast Low (ECL) occurred on May 19-25, 2009 was considered as an extreme event at Gold Coast, Australia. This paper discusses the process we followed to numerically simulate this event and its resulting wave heights and storm surge levels on the Gold Coast. The ECL was simulated using two local atmospheric models; RAMS (Regional Atmospheric Modeling System) and WRF (Weather and Research Forecasting) models. The resulting wind and pressure fields were input to a set of regional and local hydrodynamic (Mike21 HD) and spectral wave (Mike21 SW) models. The results of the model were compared with available buoy and tidal gauge records in the area to investigate the accuracy of the model results. Coastal regional inundation maps were produced based on predictions of flood level using ocean surge levels as tail water conditions. This study helps coastal zone management in terms of coastal vulnerability to flooding. The effects of Sea Level Rise (SLR) can also be considered in this study.
\end{abstract}




\section{Introduction}

ECLs are intense low-pressure systems that occur on average several times each year off the east coast of Australia. They may form in a variety of weather situations. In summer they can be ex-tropical cyclones. At other times of the year, they will most often develop rapidly just offshore within a pre-existing trough of low pressure due to favourable conditions in the upper atmosphere. ECLs may also develop in the wake of a cold front moving across from Victoria into the Tasman Sea. The sea surface temperature gradients associated with the warm eddies of the East Australian Current also contribute to the development of the lows. ECLs can generate gale or storm force winds along the coast and adjacent waters, heavy widespread rainfall leading to flash and/or major river flooding, very rough seas and prolonged heavy swells over coastal and ocean waters that can cause damage to the coastline (Callaghan, 2009).

\section{Motivation}

The May 2009 East Coast Low event (19-25 May) was significant in that it caused large seas over a wide area of the east coast of Australia. Wave rider buoys recorded significant wave heights of over 5 meters between the Sunshine Coast and Sydney. The flood crisis in the south east Queensland was the worst since the 1974 floods that devastated many parts of Brisbane. Disastrous flooding and damaging winds also occurred in south east Queensland and north east New South Wales. For the Gold Coast, ECLs of this strength and impact occur on average of every 5 years.

The frequency of May 2009-like ECLs urged us to numerically simulate this event to estimate the flood levels to provide inundation maps for the Gold Coast. Figure 1 shows the study area and available buoy and tidal gauge measurements in this area.

\section{Meteorological modeling}

High-resolution meteorological modeling reproduces features of small-scale wind and pressure fields that are too small to be resolved by global atmospheric models but observed in satellite images. Therefore, running local atmospheric models provide better wind/pressure fields for surge/wave modelling.

Two local meteorological models, WRF and RAMS, were both configured with three nested domains over the east coast of Australia. The inner domain of each model covers an area of $1900 \times 1700 \mathrm{~km}$ with a horizontal grid spacing of $4.5 \mathrm{~km}$. Both models were initialized throughout their domains using meteorological analysis fields, then forced only at the boundaries of the outer domain for the duration of the model run. The WRF model was initialized and forced with NCEP FNL analyses and the RAMS model was initialized and forced with BOM LAPS analyses. The model outputs include wind components at $10 \mathrm{~m}$ above sea level and mean sea level pressure fields. These fields are used to force the storm surge model.

Figure 2 shows three telescoped domains, nested down at 3:1 grid size ratio considered for modeling with WRF. Domain 3 covers entire domain of Gold Coast storm surge regional model. 


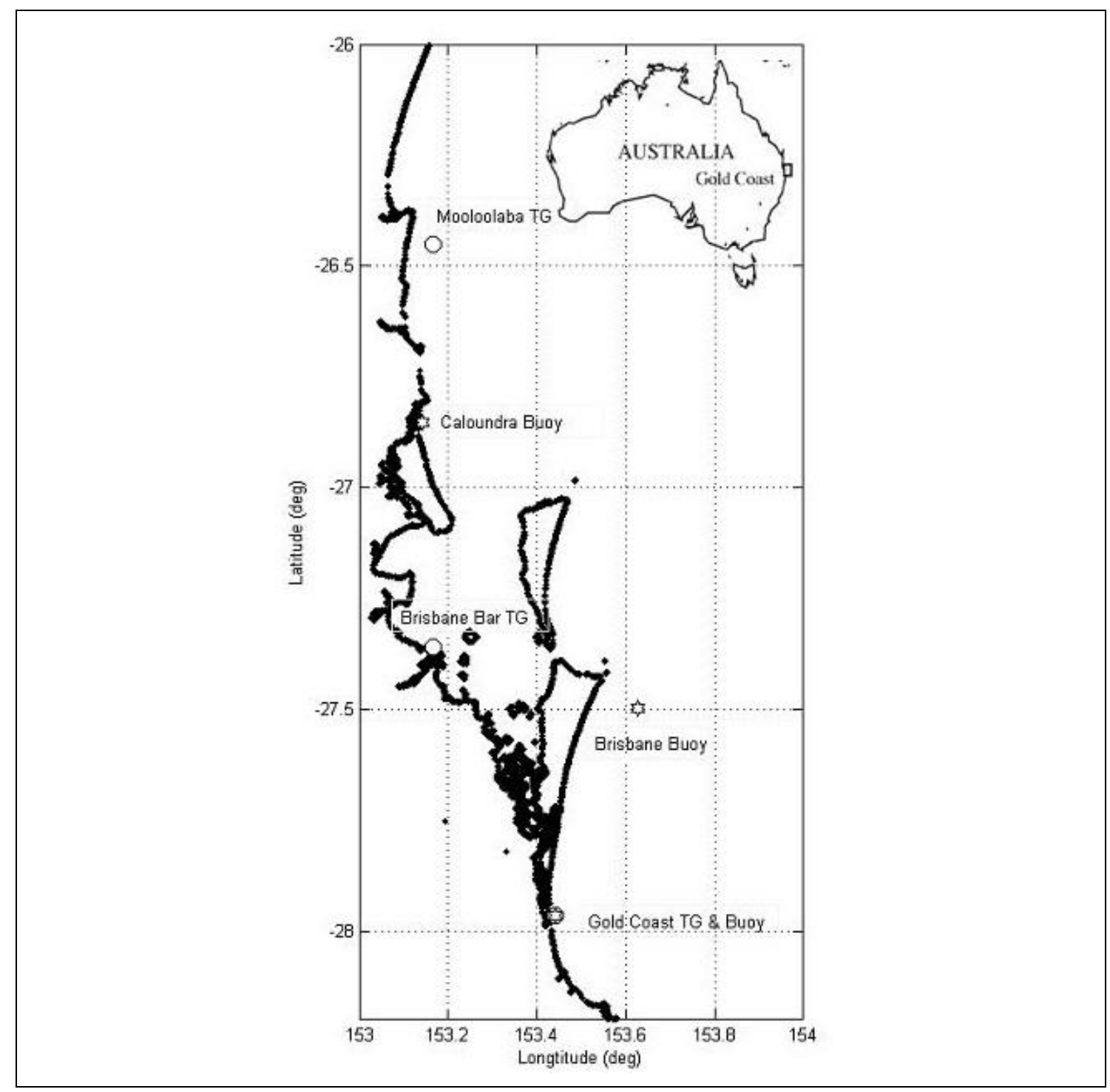

Fig. 1. Study area and available tide gauge and buoys in the area (TG: Tidal Gauge) 


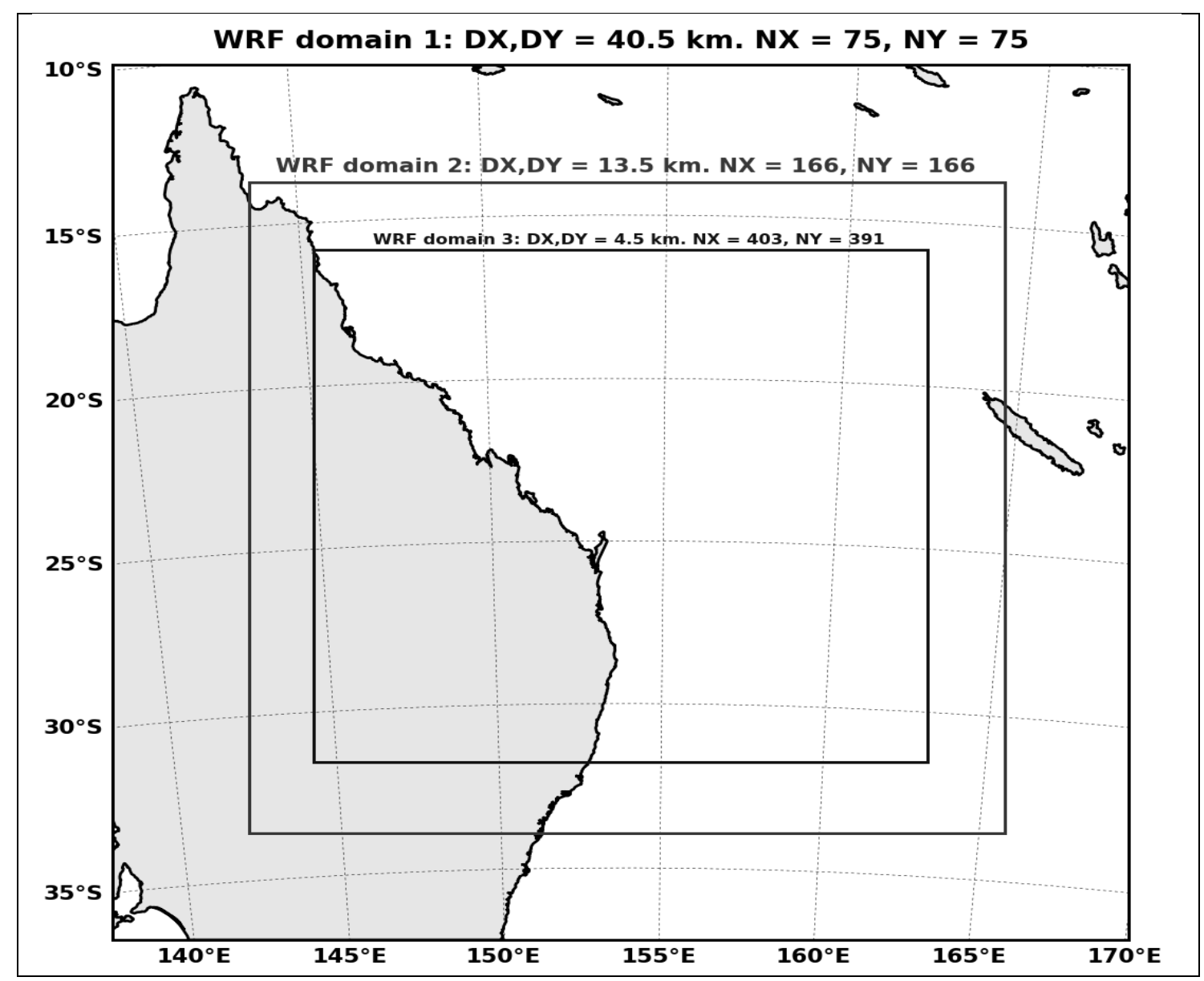

Fig. 2. Nested domains considered for WRF model

\section{Storm surge modeling}

The storm surge model includes a set of regional and local HD and SW models (Davis, 2008). These models have unstructured meshes. Regional models cover the same area as atmospheric models with mesh size of 20 to $0.1 \mathrm{~km}$ while the local models cover an area of approximately $80 \times 25 \mathrm{~km}$ with mesh size of $2 \mathrm{~km}$ to $20 \mathrm{~m}$. Figures 3 and 4 show the regional and the local mesh files, respectively. These set of models were run for each wind field, from the WRF and RAMS outputs in the following order (Figure 5):

1) Regional HD model using the simulated wind and pressure fields.

2) Regional SW model using the simulated wind field and surface elevation map from the regional HD model.

3) First local HD model: Water level boundaries (wind induced surge boundaries) extracted from the regional HD model results combined with pure tidal signal to generate storm tidal boundaries will be forced on the local HD model and run. Figure 6 shows generation of local HD boundary condition for the most offshore point of northern boundary.

4) Local SW model: Surface elevation map from the local HD model results, as well as wave energy spectrum boundaries extracted from regional SW results, are forced to the local SW model and run. 
5) Second local HD model: Wave radiation stress map from the local SW model as well as storm tidal boundaries (same as step 3) are forced on the local HD model and run.

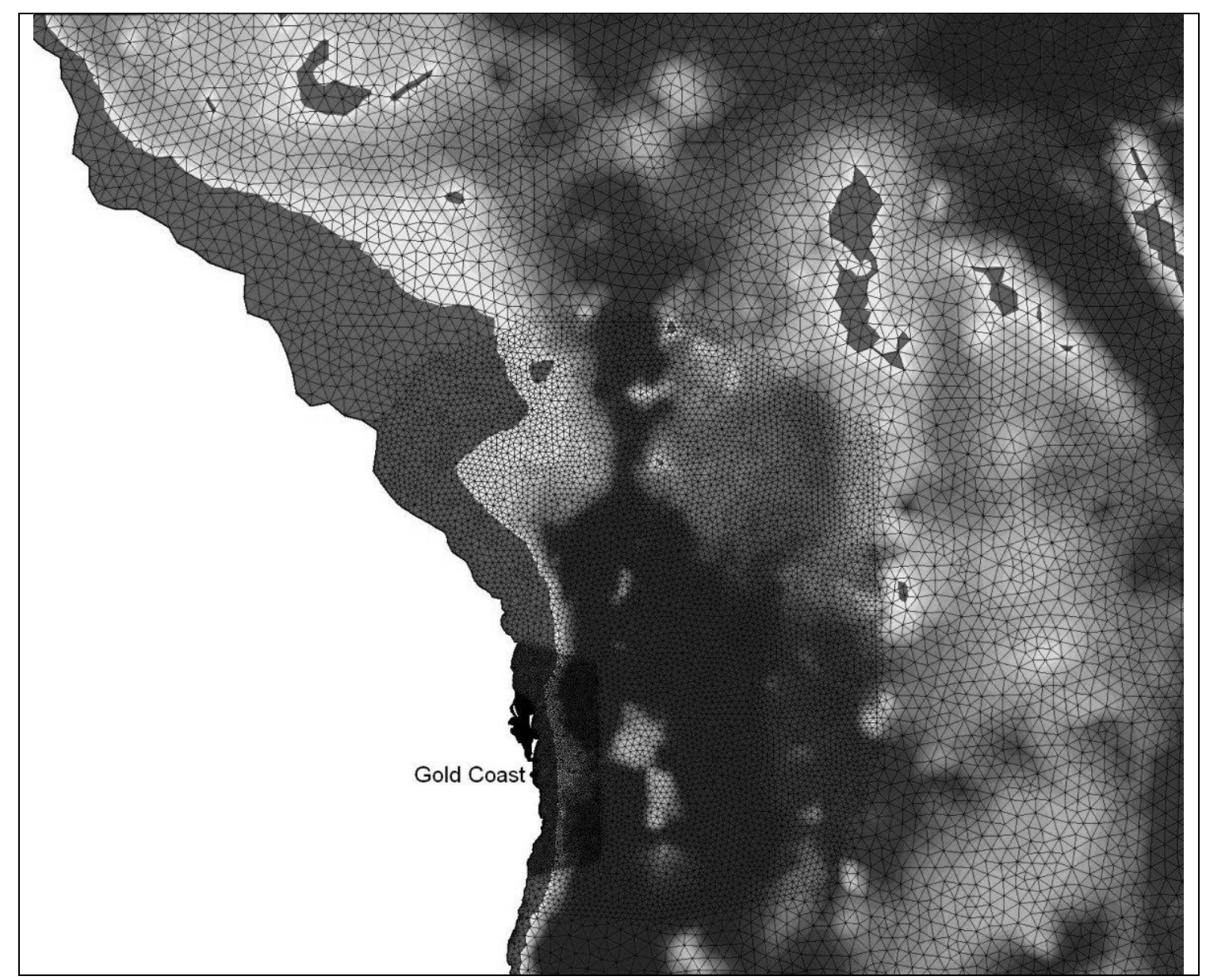

Fig. 3. Regional mesh for HD and SW models including 21603 nodes and 41917 elements 


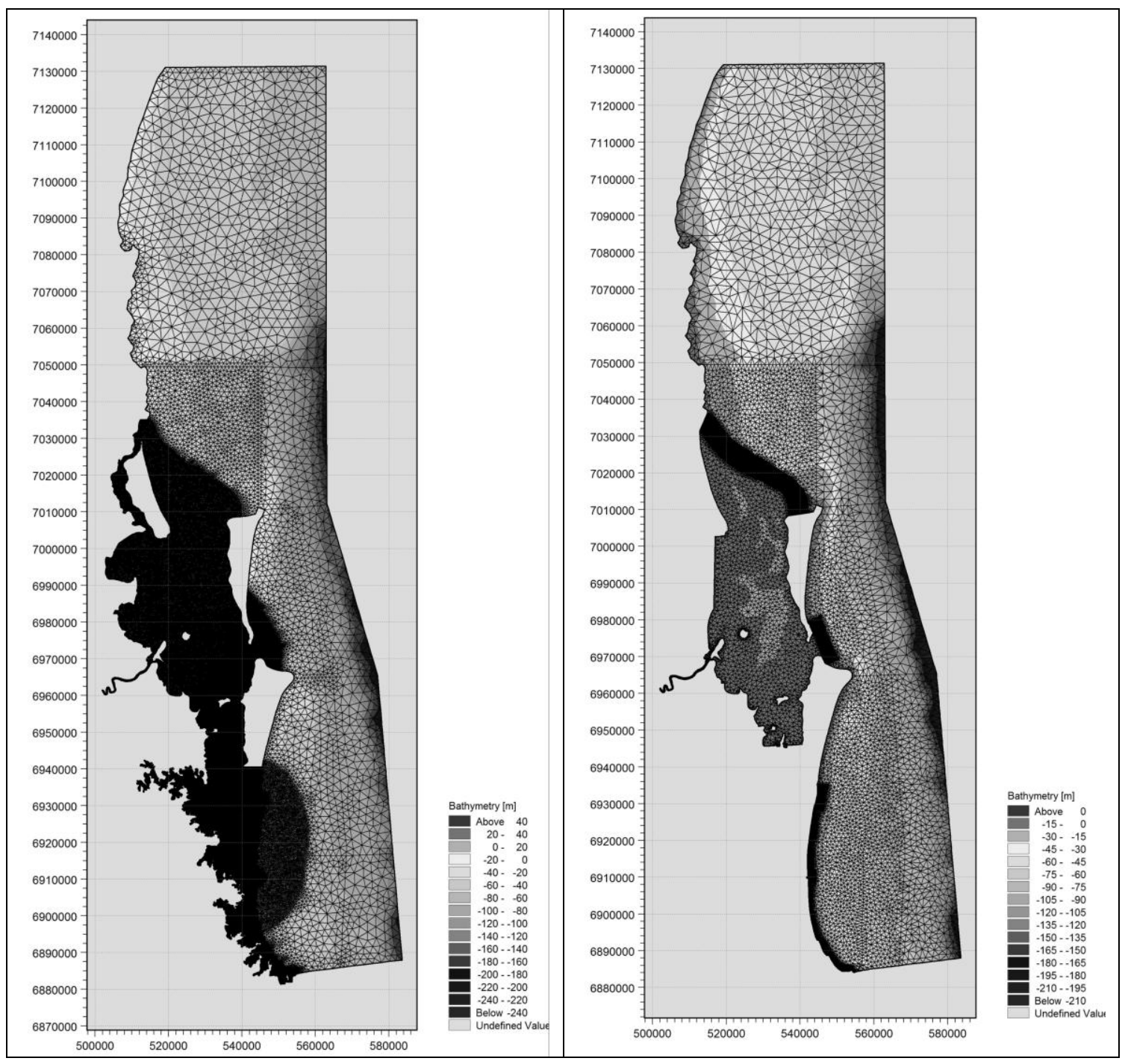

Fig. 4. Left: Local HD mesh including 236289 nodes and 465508 elements, Right: Local SW mesh including 14592 nodes and 22261 elements

\section{Model verification}

Some of the results of model verification for Gold Coast buoy are shown in Figure 7 as an example. According to this figure and results of other buoys, generally the result of the model (including significant wave height, peak wave period and mean wave direction) which was forced by WRF wind field has better agreement with measurements. The results of storm tide level from the WRF model also have better agreement with tidal gauge measurements than RAMS model. Therefore, it was decided to consider the results of WRF model in this study. Figure 8 shows the comparison between the model results forced by RAMS and tidal measurement at the Brisbane Bar.

\section{Model results}

Figure 9 shows the map of maximum significant wave height and maximum storm tide generated during May 2009 ECL. The inundation maps are prepared based on the storm tide level map and coastal topography data. According to these figures, maximum 
significant wave height of 5 meter and maximum storm tide level of $2 \mathrm{~m}$ was generated near to Gold Coast.

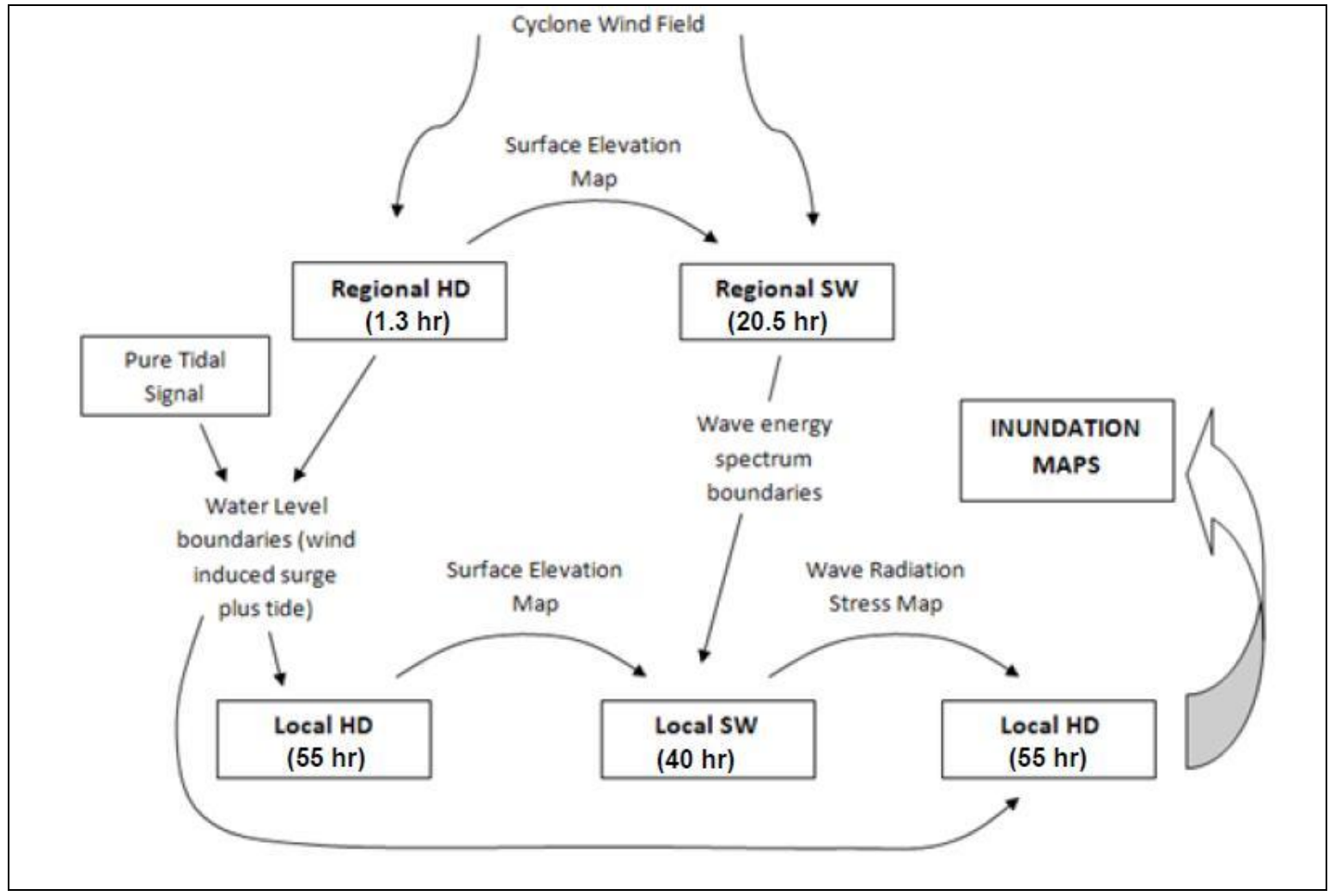

Fig. 5. Storm surge modeling approach and elapsed running time

(PC specifications: DELL PRECISION T7400, $2.83 \mathrm{GHz}$ (2 processors) CPU and 8G RAM)

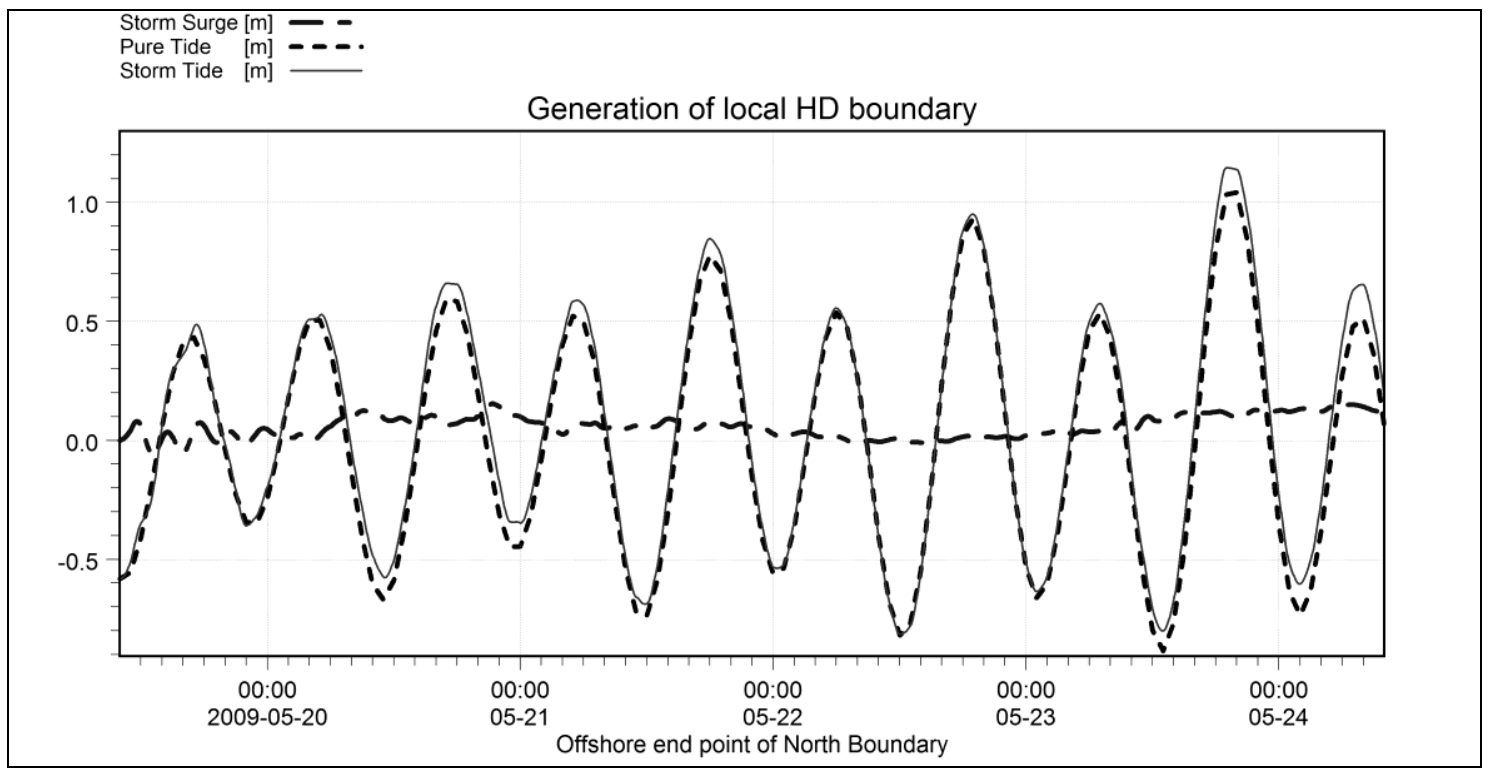

Fig. 6. Generation of boundary condition for northern boundary of the local HD model 


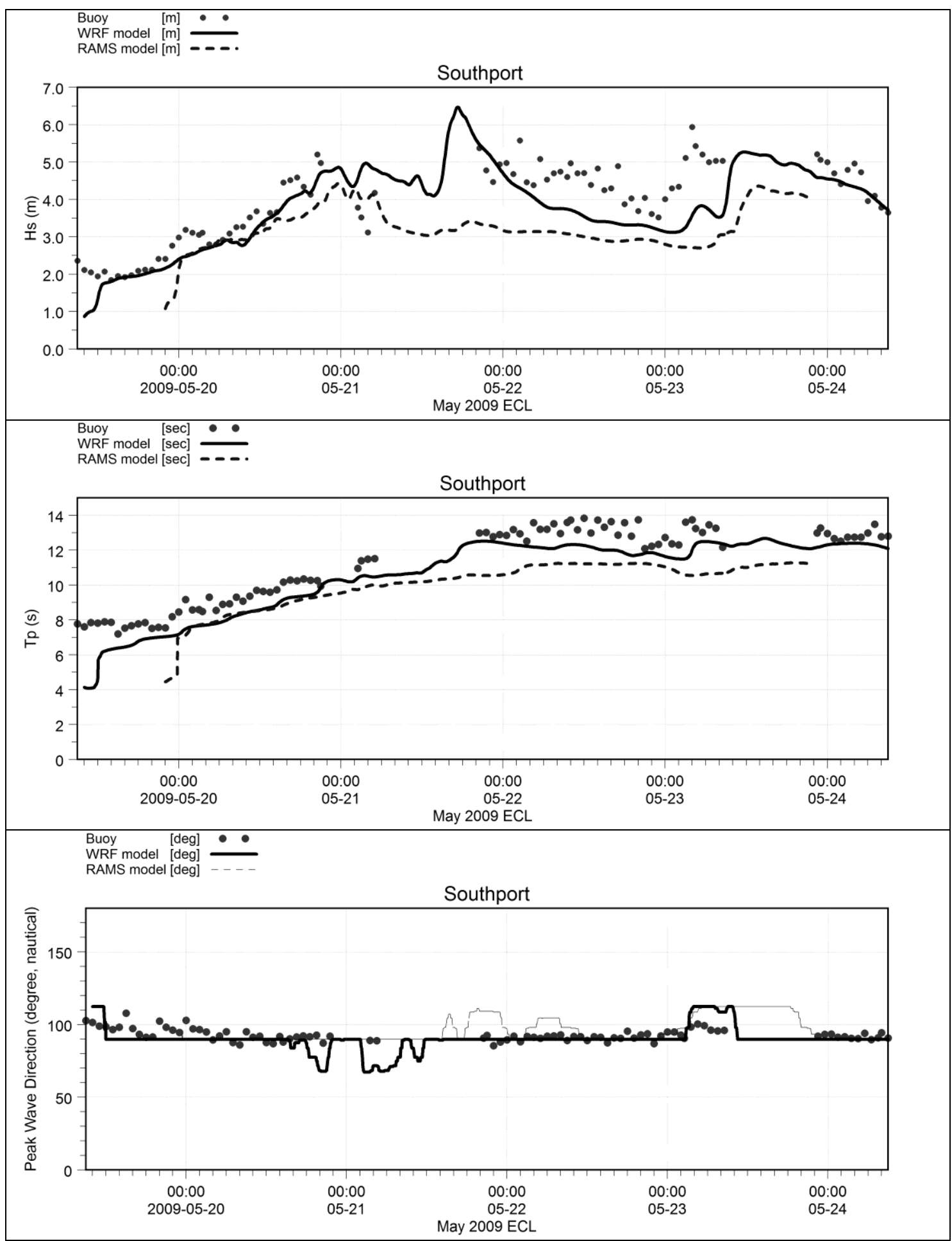

Fig. 7. Comparison of model results forced by WRF and RAMS outputs with Southport buoy records 


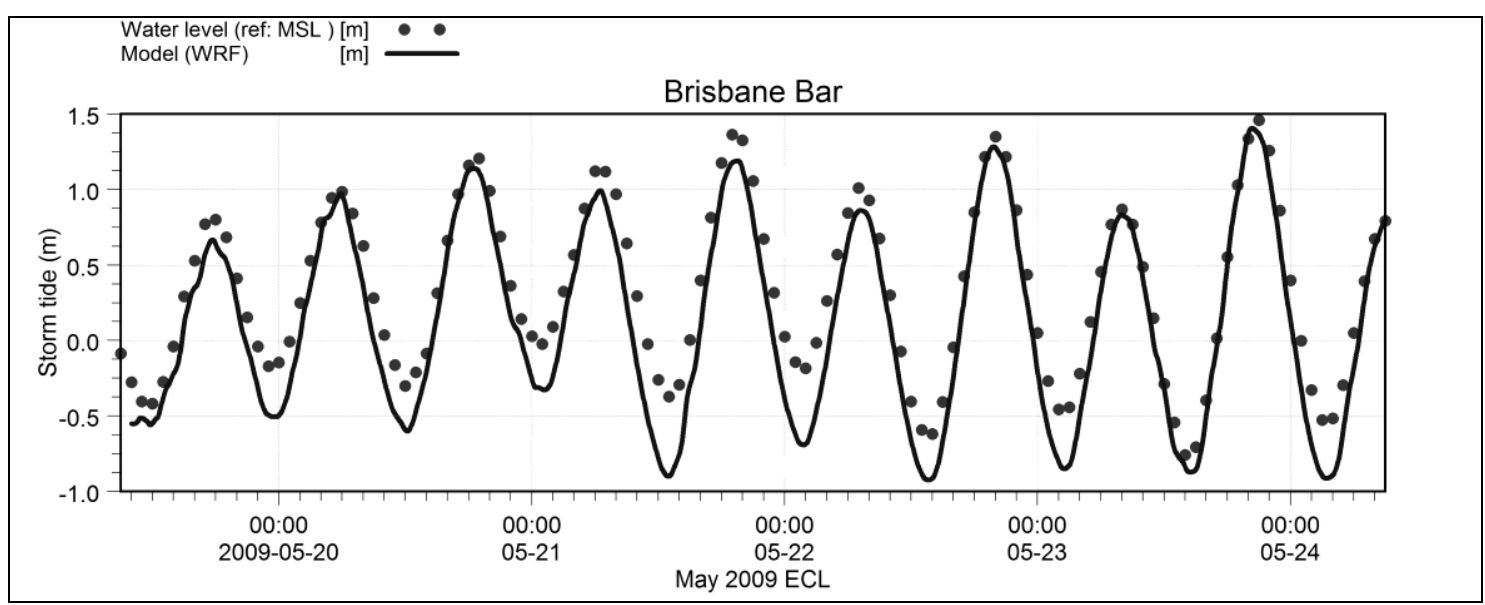

Fig. 8. Comparison of model result forced by WFR output with Brisbane Bar tide gauge

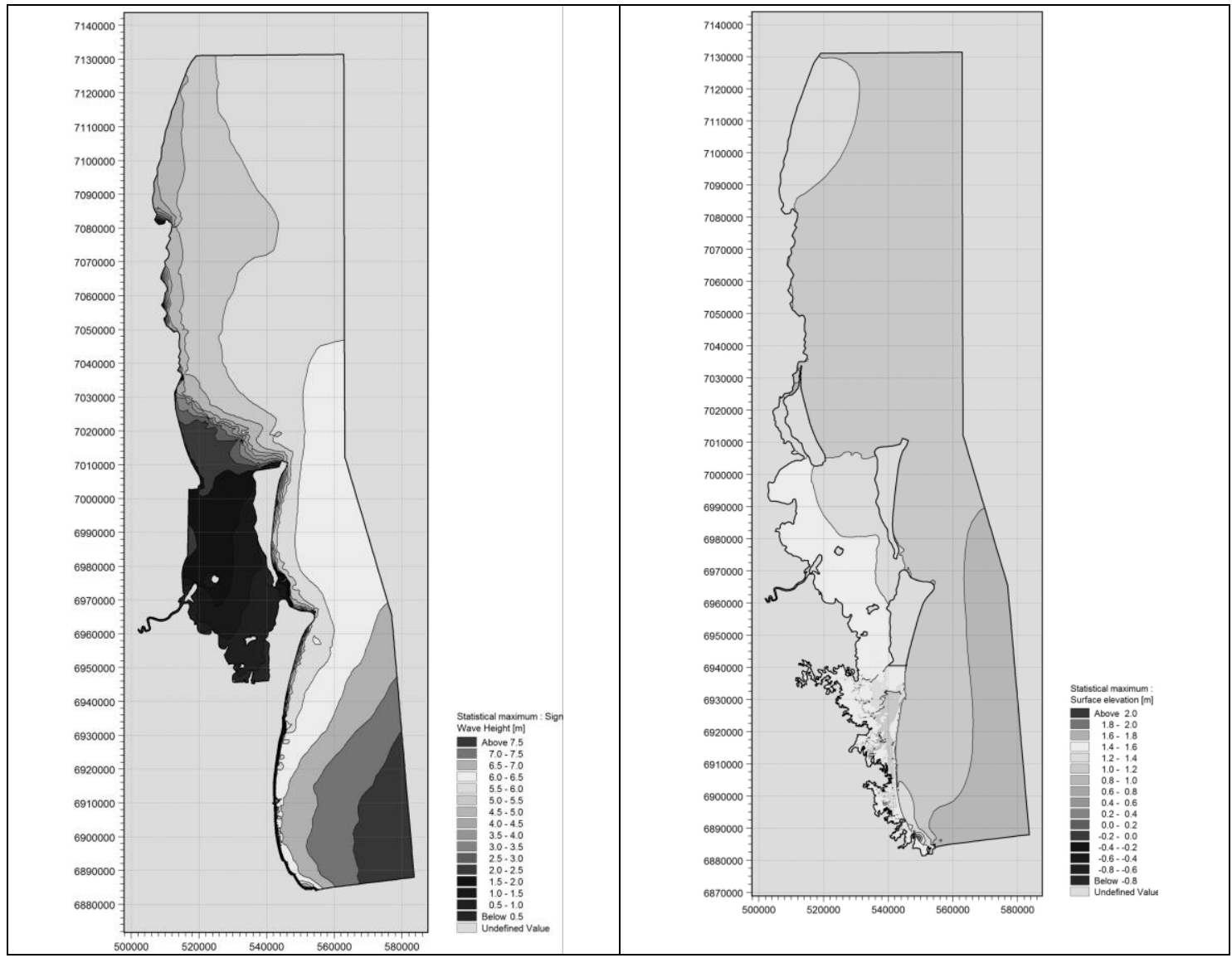

Figure 9. Maximum of significant wave height (Left) and storm tide level (Right)

\section{Effect of tides and wave setup}

The total water level at the coast resulting from a storm consists primarily of contributions from the storm surge and astronomical tide. Due to nonlinear interaction of bottom friction with ocean currents, sea level heights due to the combination of the positive tide and positive surge are generally lower than the sum of the individual 
components. For this reason tidal forcing is explicitly considered in the model simulation. Waves also contribute to coastal sea levels during storms. The net effect of breaking waves at the coast produces wave setup and individual breaking waves produce wave run-up. Wave setup is also explicitly modeled in the present study. Hubbert and McInnes (1999) suggested that an allowance for wave setup can be made by increasing the storm surge component of the storm tide level by $10 \%$. (The storm surge component is determined by recalculating the tidal contribution at the point of interest and subtracting this value off). The result of our study shows that adding this allowance to the results of first local HD model is close but slightly higher than the results of second local HD model. It means that this suggestion is conservative and can be considered when there is lack of time for running the whole storm surge model set. Ignoring the second local HD model and adding this allowance instead decreases running time by 30 percent which is important for forecasting and warning purposes.

\section{Conclusion and future work}

A storm surge model set that explicitly considers tides and wave radiation stress gradients was setup and calibrated against the May2009 ECL. This model does a better job when forced by WRF wind and pressure fields than when forced by RAMS wind and pressure fields.

Running model without second local hydrodynamic model and considering an allowance for the effects of wave radiation gradients instead is conservative, however, decreases the computation times which is important for the storm surge forecasting and warning purpose.

Inundation maps can be prepared based on the results of storm surge model for the coastal zone management purpose.

The effect of SLR (sea level rise) can be considered in the model. This can be easily performed by adding the SLR value to the bathymetry depth values. Then inundation maps can then be provided for consideration of the sea level rise scenarios.

\section{Acknowledgements}

The authors would like to thank D. Metters from Maritime Safety Queensland for providing water level data and C. Acworth from DERM (Department of Environment and Resource Management) for providing buoy data. Funding for this research was provided by the Queensland Smart State Innovation Fund and Griffith University.

\section{References}

Callaghan, J. (2009). "The East Coast Low May19-25, 2009”, http://www.coastalwatch.com/news/article.aspx?articleId=5865.

Davis, S. (2008), "Storm tide decision support system Report", DHI Australia.

Hubbert, G.D. and McInnes, K.L. (1999). "A storm surge inundation model for coastal planning and impact studies", J. Coastal Research.15, 168-185. 